\title{
Federal Wi-Fi safety report is deeply flawed, say experts
}

A new review of Health Canada's safety standards for radiofrequency devices, including $\mathrm{Wi}-\mathrm{Fi}$ and cellphones, is deeply flawed because of the authors' conflicts of interest and lack of expertise, say two scientists. The Royal Society of Canada's (RSC) Expert Panel Report on the Review of Safety Code 6: Potential Health Risks of Radiofrequency Fields endorses current safety standards while calling for more research. The RSC invited the two scientists to peer review the report.

The RSC's eight-member panel "actively blinded themselves to vital evidence," says Martin Blank, an expert on the effects of electromagnetic radiation and special lecturer at the Columbia University Medical Center in New York City. "The panel's position on maintaining the current standards is so fixed that it leads them to conclusions one would never expect from policy officials in the field of health," Blank added in an interview. "I am almost certain that the reluctance of the panel to be guided by biological evidence reflects a lack of expertise in cell biology.'

Dr. Anthony B. Miller, professor emeritus at the University of Toronto's Dalla Lana School of Public Health, was likewise critical. The panel included members with "major links to the telecommunications industry," says Miller. "This is a conflicted panel, with insufficient expertise in epidemiology. It ignored recent evidence that wireless radiation is a probable carcinogen."

Miller flagged concerns about the panel last summer after a CMAJ article revealed that the RSC panel's original chair, Daniel Krewski, failed to disclose to the society that he had received a \$126 000 contract in 2008-2009 from
Industry Canada. Krewski was replaced as panel chair.

Amid concerns about links between the telecommunication industry and John Moulder, professor and director of radiation biology at the Medical College of Wisconsin, in Milwaukee, two members of the original panel stepped down and were also replaced. Moulder remained on the panel.

These changes to the panel remained unsatisfactory, says Miller. "It is unfortunate that the Royal Society failed to

[extremely low-frequency fields]. To do the job right, the panel should be reconstituted to include members having the expertise needed to evaluate the biological research and to formulate safety standards that take into account the biological indicators of EMF danger levels."

Instead of outsourcing the safety review to the RSC, which is not subject to government accountability and transparency rules, Miller suggests that Health Canada should conduct the safety review internally, using traditional expert advisory panel review procedures, which are more accountable. "That is a process that is far better.'

Frank Clegg, CEO of Canadians for Safe Technology (C4ST), an Oakville, Ontario-based advocacy group that campaigns against the dangers of exposure to unsafe levels of wireless radiation from technology, says the RSC's panel was "an expensive exercise that was corrupted by industry and so is a waste of taxpayer dollars."

Russel MacDonald, officer on expert panels at the RSC in Ottawa, Ont., did not respond to an interview request.

Sarah Lauer, a media officer with amend the membership of the panel as requested by some of us."

After reviewing the panel's final report, Miller and Blank now say that the RSC, which was paid $\$ 100000$ by Health Canada to establish the review panel, failed in its obligation to the public.

"This is actually a failure of the panel to fulfil its primary function - to protect the health of the population," says Blank. "This failure is occurring in an environment with increasing exposure to a wide range of non-ionizing EMF [electromagnetic fields], including ELF

Health Canada, says the department is reviewing the panel's Apr. 1 report and "will consider the RSC's recommendations, as well as all feedback received during the upcoming public consultation on Safety Code 6." The revised code is expected to be published in the fall of 2014. The RSC, she added, "notes that there are no established adverse health effects at exposure levels below the proposed limits." - Paul Christopher Webster, Toronto, Ont.

CMAJ 2014. DOI:10.1503/cmaj.109-4785 